DOI: http://dx.doi.org/10.22483/2177-5796.2017v19n1p69-85

\title{
O uso dos jornais religiosos como fonte para a história da educação
}

\author{
Adriana Duarte Leon
}

Resumo: O objetivo deste trabalho é apresentar algumas possibilidades de contribuição da imprensa religiosa como fonte para os estudos na área de história da educação. A fim de desenvolver tal argumento, analisaremos três jornais católicos que circularam no Rio Grande do Sul, no início do século XX: o jornal "Estrella do Sul", produzido pela arquidiocese de Porto Alegre; o jornal "Staffetta Rio-grandense", produzido pela ordem dos Capuchinhos, em Caxias do Sul e o jornal "A Palavra", produzido pela diocese de Pelotas. No que tange à educação, as construções discursivas são muito diretas e disputam uma concepção de educação católica para a escola pública.

Palavras-chave: Imprensa religiosa. História e educação.

\section{Use of religious journals as source for history of education}

Abstract: The objective of this paper is to present some possibilities of contribution of religious press as a source for studies in the history of education. In order to make this argument stronger, we will analyze three Catholic journals that had circulated in Rio Grande do Sul, in the early twentieth century: the journal "Estrella do Sul", produced by the Archdiocese of Porto Alegre; the journal "Staffetta Rio-grandense", produced by the Capuchins Order, in Caxias do Sul, and the journal "A Palavra", produced by the Diocese of Pelotas. With regard to education, the discursive constructions are very direct and dispute a Catholic education conception to public school.

Keywords: Religious press. History and education. 


\section{Introdução}

O presente trabalho visa explorar algumas possibilidades sobre a utilização da imprensa religiosa como fonte para a história da educação. De forma específica, trataremos de três impressos católicos que circularam no início do século XX, no estado do Rio Grande do Sul. São eles: o jornal "Estrella do Sul", o jornal "Staffetta Rio-grandense" e o jornal "A Palavra". Os impressos citados apresentam vínculo direto com a Igreja Católica e se autoproclamam como os propagadores oficiais desta Instituição no estado.

Os impressos católicos se consolidaram, no início do século $\mathrm{XX}$, como parte de uma estratégia ampla de intervenção da Igreja Católica, que buscava agregar em si uma potencialidade a fim de consolidar formas de pensar e agir. O impresso visava intervir de forma efetiva no cotidiano das famílias brasileiras e agregava em si a possibilidade de levar as orientações da instituição a regiões que o pároco, por vezes, não acessava, considerando a dificuldade de percorrer algumas regiões do país no período. Em alguns casos, o impresso anuncia o seu objetivo e compromete o leitor católico ou simpatizante a realizar sua leitura, bem como considerar a sua orientação: "O guia e consultor das famílias Católicas, para 1930, deve ser o Almanaque Estrella do Sul” (ESTRELLA DO SUL, 2 fev. 1930, p. 1).

Para a historiografia, os impressos são uma fonte em potencial, pois apresentam as disputas do meio social de forma dinâmica, detalhada e gradual, possibilitando ao leitor, descolado do tempo de sua produção, imergir nas polêmicas de um tempo passado. Alves (2001, p. 4), ao tratar da história política, afirma que, por meio dos "jornais os conflitos políticos encontram seu espaço de propagação, chegando o jornalismo a servir como elo ou agente de combate entre diferentes tendências político-ideológicas”.

A utilização da imprensa de circulação diária ou semanal como fonte possibilita uma análise sociopolítica do período, pois por ela é possível perceber parte dos conflitos e as disputas locais que, não perdendo de vista a conjuntura nacional, explicam as singularidades regionais. Considerando a dinamicidade e a intensidade deste tipo de produção impressa, é relevante destacar que a possibilidade de estabelecer conexões entre o local e o global está atrelada ao potencial analítico do pesquisador, que estabelece inteligibilidade às particularidades, possibilitando, assim, o entendimento do cotidiano apresentado no impresso. A utilização da imprensa como fonte exige do pesquisador apropriar-se, na medida do possível, das condições 
histórico-sociais em que foram produzidos os documentos; caso contrário, corre-se o risco de produzir uma descrição sem consciência dos conflitos ali explícitos.

A análise da imprensa permite apreender discursos que articulam práticas e teorias, que se situam no nível macro do sistema, mas também no plano micro da experiência concreta, que exprimem desejos de futuro ao mesmo tempo em que denunciam situações do presente. Trata-se, por isso, de um corpus essencial para a história da educação (NÓVOA, 1997, p. 11).

O surgimento e o desenvolvimento da imprensa no Brasil acompanham e vinculam-se às transformações ocorridas nos espaços públicos, à modernização política e cultural, ao processo de independência e de construção de um Estado Nacional. Considerando tais questões, compreendemos a imprensa como uma construção discursiva que é portadora e produtora de significações. Assim como nos sugere Vieira (2007), o jornal constitui-se como um instrumento pedagógico eficiente à universalização do ethos moderno e, neste sentido, também explicita algumas das ideias modernizadoras concernentes aos modos de vida.

Os jornais, com periodicidade diária ou semanal, são acessados de forma muito intensa. Considerando aqui o baixo custo de produção e, consequentemente, o baixo custo de aquisição deste tipo de publicação, cumula-se a isso a possibilidade de uma leitura rápida, de fácil apreensão, conteúdo direto, útil e variado. Levando-se em conta tais particularidades, a imprensa se constituiu em um movimento de larga escala que alterou a forma de organização da vida social, e que também anunciava o cenário político, os movimentos e os grupos organizados em emergência.

Participar da fase do periodismo no Brasil era algo fundamental para qualquer setor que pretendesse estabelecer a intervenção no meio social; abdicar deste espaço era se colocar à margem do mecanismo que pautava as principais polêmicas e disputas do país. A Igreja Católica estabelece sua intervenção englobando a imprensa e projeta uma estratégia para esse setor, que contempla a criação da Liga da Boa Imprensa, com jornalistas católicos e uma forte campanha em prol das assinaturas de revistas e jornais.

No que se refere à imprensa religiosa, de forma específica aos impressos católicos, é necessário destacar que, na primeira metade do século XX, a Igreja Católica cria uma série de estratégias com o objetivo de retomar espaço no campo social e, por meio de tais estratégias, estabelece um diálogo com os interesses do Estado e intensifica a romanização da Igreja Católica 
no Brasil. As informações que circulam nos impressos católicos constroem representações sobre fatos, contextos e conflitos e disputam a adesão do leitor a essas representações.

De acordo com Magaldi (2010), os impressos católicos têm-se mostrado como importante fonte e objeto de pesquisa para a história da educação, pois se consolidavam atendendo à indicação nacional e contemplando as particularidades locais; assumiam um caráter doutrinário, explicitando, assim, muito das tensões presentes no projeto católico. A imprensa é o meio de comunicação de maior circulação no início do século XX e, buscando participar deste espaço, a Igreja mantinha nacionalmente algumas publicações e estimulava a publicação de impressos regionais com o objetivo de orientar os católicos e simpatizantes.

Resguardada a característica didático-pedagógica, os jornais católicos no período citado estavam espalhados por vários estados brasileiros e se consolidavam em verdadeiros "apóstolos" da Igreja Católica. Considerando a dificuldade em acessar algumas regiões do país, o periódico representava a Igreja em lugares aonde o pároco não chegava.

\section{A ampliação da Imprensa Católica}

A intensificação do investimento católico na imprensa é motivada pela necessidade de ampliar espaço de intervenção social e pela possibilidade de combater a ideia de um Estado laico presente na primeira constituição republicana e vigente até a década de 1930. Na tentativa de recatolicizar o Brasil, a Igreja Católica reorganiza-se internamente e estabelece novas frentes de atuação, com o objetivo de manter-se como espaço de referência religiosa e cultural no país. Para viabilizar tal intervenção, foi necessária a rearticulação dos discursos e das práticas, em que a Igreja buscou adaptar-se ao processo de modernização como estratégia de disputa pelo espaço que considerava perdido ou em disputa.

A Igreja Católica estabelece sua intervenção, englobando a imprensa e consolida uma estratégia para esse setor que contempla a Liga da Boa Imprensa e a organização de um coletivo de jornalistas católicos que subsidiam o conteúdo dos jornais regionais. A imprensa se efetiva como um movimento de ampla abrangência que modificou a percepção do meio social e a correlação de força entre os grupos em emergência. 
A imprensa de caráter confessional, especificamente a católica, não podia ficar à margem de todo esse movimento de fundamentação, avaliação e interpretação históricas de periodismo. Primeiramente porque, em nível religioso, a produção impressa marcou, em graus ainda a aquilatar corretamente, a presença e a ação da Igreja sobre a sociedade brasileira. E, em segundo lugar, porque a imprensa, sobretudo os periódicos, foi canal privilegiado, utilizado bem ou mal pela hierarquia e pelos católicos, para defender a fé e os costumes, para reivindicar direitos, para lutar contra os adversários e, em uma palavra, para formar e informar (LUSTOSA, 1983, p. 8).

Os jornais produzidos pela imprensa católica se caracterizam pelo posicionamento claro sobre as questões de interesse da Igreja Católica. O posicionamento ambíguo se restringe a questões que são indiferentes aos interesses do catolicismo. Sobre a imprensa católica, de forma geral, Lustosa (1983) destaca a pretensão de produzir um diário católico nacional, que embora tenha feito parte do debate da boa imprensa, em alguns momentos, não adquiriu materialidade. A estratégia estabelecida na produção de jornais católicos foi estimular a produção de jornais estaduais e/ou regionais e subsidiar teórica e estruturalmente esses impressos por meio da Boa Imprensa.

No que se refere à produção de revistas, a Igreja Católica mantinha, em âmbito nacional, algumas publicações que circulavam de forma mais abundante na região central do país, constituindo-se a cidade do Rio de Janeiro como espaço prioritário para a produção e a circulação desse material. Dada a necessidade de ampliar a produção e a circulação da imprensa católica no Brasil, a Igreja estimula a publicação de impressos regionais, possibilitando a ampliação da pauta nacional, bem como o atendimento às particularidades locais. Tal estratégia, ao mesmo tempo em que implementa um projeto de abrangência nacional, torna os impressos católicos mais interessantes para o leitor que vê neles sua realidade retratada.

No intuito de oferecer 'boas leituras' e de intervir no espaço público, a Igreja Católica mantinha nacionalmente a Revista “A Ordem”, órgão do Centro Dom Vital; o "Boletim da Associação dos Professores Católicos”, que começou a circular em 1932 e, em 1934, foi substituído pela "Revista Brasileira de Pedagogia", que se propunha a discutir as diversas questões relacionadas ao ensino e ampliar o debate acerca dos pressupostos anunciados nas encíclicas papais.

Além dos impressos promovidos pela instituição, nota-se a presença das ideias defendidas pela Igreja Católica em impressos não católicos, o que ocorria pela provável correlação de força presente na composição política que orientava a produção do impresso. Cito como exemplo a Revista do Ensino de Minas Gerais, que começa a circular em 1925. Era uma produção da 
Diretoria de Instrução Pública do estado e explicita, no início da década de 30, o acordo com algumas das ideias defendidas pelo catolicismo, principalmente no que se refere à educação. "Os princípios religiosos estavam em consonância com os princípios norteadores das novas diretrizes educacionais mineiras, principalmente nos aspectos relacionados à formação moral e disciplinar" (BICCAS, 2008, p. 64).

A revista do Ensino de Minas Gerais, assim como diversos outros impressos espalhados pelo Brasil, divulgava as ideias católicas, sem manter uma veiculação específica do impresso com a Igreja. Tal intervenção pode ser atribuída à relação política estabelecida pela Igreja Católica, que variava de estado para estado, ao crescimento de um laicato católico intelectual que apresentava influência junto a espaços significativos da sociedade, como, por exemplo, a imprensa; a organização interna da Igreja Católica que estimulava a disputa nos meios de comunicação da época e, por fim, a identidade cultural da população brasileira com o catolicismo.

Como já dito, além das produções nacionais, a Igreja Católica estimulava a publicação de impressos regionais com o objetivo de ampliar o diálogo da instituição com a sociedade. Tal orientação propiciou o surgimento de diversos impressos católicos no Brasil. Em conformidade com essa estratégia, no Rio Grande do Sul, foi produzida uma gama variada de impressos. Destacam-se, nesta análise, três jornais que circularam no período, os quais demonstram a ampliação da imprensa católica e permitem analisar a disputa de um ideário de educação para o país.

\section{A organização eclesiástica da Igreja Católica no Rio Grande do Sul e os jornais em análise}

A Igreja Católica Ultramontana adquiriu organicidade no Rio Grande do Sul em meados do século XIX. A primeira diocese data de 1848 e tinha como objetivo consolidar e ampliar a estrutura eclesiástica no sul do Brasil. A diocese estava subordinada ao Rio de Janeiro e apresentava organicidade limitada, considerando a precariedade estrutural e humana. No início do 
Século XX, mais precisamente em 1910, a Igreja Católica estabelece uma reorganização da estrutura eclesiástica no país e são criadas novas dioceses e arquidioceses; seguindo essa lógica, o estado do Rio Grande do Sul foi dividido geograficamente em quatro grandes blocos: a diocese de Porto Alegre foi elevada a arquidiocese e foram criadas a diocese de Pelotas, a diocese de Santa Maria e a diocese de Uruguaiana. Tal divisão vigorou até o final de 1934, data da criação da diocese de Caxias do Sul. Ainda no final da década de 30 foi criada a diocese de Vacaria; tal divisão vigorou até meados do século XX.

A criação de dioceses ou a diocesanização foi um estratégia encontrada pela Igreja Católica, na segunda metade do século XIX, na Europa, para compensar a perda dos territórios eclesiásticos na península itálica e em outros lugares. Implementa-se uma territorialidade religiosa que pretendia recortar o mundo em dioceses, prelaturas, paróquias etc. No Brasil, a partir de 1910, nota-se de forma explícita a ampliação da estrutura eclesiástica e uma crescente diocesanização do país.

O Rio Grande do Sul foi o décimo estado do país a fundar uma diocese, como bem nos mostra Souza (2000) ao analisar a expansão da Igreja Católica no país. Os primeiros anos da diocese de Porto Alegre foram de atuação muito limitada e somente no início do século XX, com a elevação da diocese de Porto Alegre a arquidiocese e com a criação de outras dioceses, é que a organização eclesiástica ganha fôlego no estado.

Com o objetivo de garantir a organicidade nas quatro regiões eclesiásticas, foram nomeados um arcebispo e três bispos responsáveis. Em Porto Alegre, Dom Cláudio José Gonçalves Ponce de Leão foi elevado a arcebispo metropolitano, mas solicitou renúncia dois anos depois, quando assumiu Dom João Becker, que ficou no cargo por mais de três décadas. Transformou-se em uma das figuras de referência da Igreja Católica Rio-grandense na primeira metade do século XX e, em 1913, criou a revista "Unitas", editada pela arquidiocese de Porto Alegre; logo em seguida, a arquidiocese estimula a criação do jornal semanário "Estrella do Sul”. Para a diocese de Pelotas, foi nomeado Dom Francisco de Campos Barreto; para a diocese de Santa Maria, Dom Miguel Lima Valverde e para diocese de Uruguaiana, Dom Hermeto José Pinheiro. Com exceção de Dom João Becker, os responsáveis nomeados em 1910 tinham em comum o fato de, antes da nomeação, residirem fora do Rio Grande do Sul.

Uma das estratégias adotadas pela instituição para divulgar e disputar suas ideias foi a produção de impressos para circular entre a população, diversos impressos católicos, ou 
indiretamente vinculados, como, por exemplo, os jornais dos Círculos Operários, surgiram até meados do século XX no estado. Destacam-se, neste texto, três jornais que circularam no início do século XX. Embora produzidos em regiões diferentes do Estado, estão vinculados à Igreja Católica e anunciam questões relevantes sobre o debate educacional do período, são eles: O jornal "Estrella do Sul”, produzido pela arquidiocese de Porto Alegre; o jornal "Staffetta Riograndense", produzido pela ordem dos Capuchinhos em Caxias do Sul e o jornal "A Palavra", produzido pela diocese de Pelotas.

Os três jornais estudados definem de forma muito clara seu público leitor, publicam textos curtos, apresentam estrutura visual atrativa, com ilustrações e imagens; mesclam as notícias locais com a pauta nacional da Igreja Católica, investem em divulgação de eventos, tratam do cotidiano das regiões, possuem espaços reservados para os patrocinadores; enfim, disputam espaço com os jornais diários e certamente também o mesmo público leitor, um sujeito comum, que não precisa estar vinculado ao catolicismo. Os jornais podem ser adquiridos individualmente ou por assinatura mensal; por vezes são disponibilizados para aquisição em bancas. Os leitores católicos são estimulados cotidianamente a se tornarem assinantes e assim contribuírem com a divulgação da Boa Imprensa no Brasil.

Os jornais selecionados para essa reflexão apresentam em comum o vínculo direto com a Igreja Católica. Busca-se aqui perceber como a instituição utiliza a imprensa para fins de divulgar e construir um ideário de educação. A imprensa católica almejava ser um canal de comunicação entre a Igreja e o cidadão. Para estabelecer tal meta, imprimia atrativos em suas publicações, como a divulgação de receitas, curiosidades, relatos cotidianos e até piadas. Contudo, a publicação de tais atrativos não perdia de vista os objetivos que norteavam a existência da imprensa católica e, em alguns casos, funcionavam como uma alternativa discursiva lúdica que construía um padrão de conduta desejado.

\section{A educação em disputa na Imprensa Católica}

Os jornais em destaque nesta reflexão foram criados no início do século XX e seguem a lógica do movimento de reorganização da Igreja Católica no Brasil. Circularam em regiões importantes do estado e indicam representações sobre questões polêmicas do período. Em termos de construção discursiva, uma das frentes adotadas pela Igreja Católica, como destaca Almeida

Quaestio, Sorocaba, SP, v. 19, n. 1, p. 69-85, abr. 2017. 
(2007), foi associar o laicismo à desordem e, por meio deste fio condutor, estimular a construção de um determinado imaginário social sobre o ser católico. Se o laicismo representava a desordem, o catolicismo representava o inverso: a ordem e o progresso para o país.

Diversas foram as iniciativas da Igreja Católica com objetivo de reorganizar-se internamente e disputar espaço social. Destaco que a mobilização ocorrida em torno da constituição de 1934 explicita estratégias que, embora presentes em outros momentos da história, emergiram de forma acentuada pelo contexto de disputa acerca do processo constituinte. $\mathrm{O}$ debate educacional ganha destaque neste período, pois é um dos pontos polêmicos na reforma da constituição e foco de disputa pelo movimento católico. Pode-se perceber a corporificação das reivindicações em torno deste ponto, considerando algumas estratégias explicitadas nos jornais estudados.

A orientação era "recatolizar o Brasil" e disputar espaço na opinião pública; no desempenho dessa tarefa, a boa imprensa cumpre função estratégica, pois os impressos eram um espaço privilegiado de ocorrência do debate público e as ideias católicas estavam representadas e em disputa neste meio. A defesa da liberdade de ensino é uma estratégia recorrente e presente no debate educacional; o argumento mais utilizado é a afirmação da autoridade da família sobre a educação dos filhos. Nesta lógica, o Estado é compreendido como segunda instituição de autoridade no campo terreno e deve submeter-se à decisão da família.

Os impressos eram compostos por textos curtos, parábolas, avisos, orações, agendas, publicações das comunidades, trechos de encíclicas, eventos, reuniões, propagandas e notícias relacionadas ao cotidiano da região. As ilustrações apareciam comumente vinculadas às propagandas, às figuras eclesiásticas e aos prédios da instituição. O debate acerca da educação aparece de forma constante nos impressos, sendo a presença do ensino religioso nas escolas um tema recorrente; o argumento desenvolvido a seu favor era variado, embora a reprovação ao contexto laico apareça de forma muito acentuada.

O ensino religioso nas aulas

[...]. Portanto, vê-se que a religião pode e deve ser ministrada em nossas aulas, principalmente na nossa amada pátria, a qual, conforme afirmou ultimamente o Sr. Washington Luiz, se ufana de ser católica.

Se na França, Suíça, Holanda, Itália, Estados Unidos, a religião é facultativa nas aulas, por que será que, no Brasil, também não poderá ser permitida? Até na própria constituição da Alemanha protestante se lê o seguinte:

'A educação physica, moral-social da prole é dever supremo, direito natural dos pais, 
sobre cuja execução vela o Estado; a instrução religiosa é matéria ordinária do ensino nas escolas, exceção feita para as confessionais... A instrução religiosa é dada de conformidade com os da respectiva sociedade religiosa, salvo o direito de vigilância do Estado, etc.' Felizmente, o benemérito governo do Estado do Rio Grande do Sul, imitando o exemplo de Minas Gerais, vê com bons olhos o ensino religioso [...] (A PALAVRA, 13 set. 1930, p. 1).

O trecho destacado acima foi publicado no jornal "A Palavra", produzido pela diocese de Pelotas em parceria com o Centro da Boa Imprensa e circulava na região sul do estado; era divulgado como "A Palavra" a ser lida e seguida.

Em um trecho publicado no jornal "A Palavra", sob o título "Escola", percebe-se a mobilização do discurso no sentido de responsabilizar a escola laica pela formação de cidadãos desajustados socialmente, reforçando assim a ideia de laicismo como algo negativo.

\footnotetext{
A Escola

Abri escolas e fechareis prisões - exclamou em prosa e verso os progressistas do século XIX - o século das luzes. Nunca houve doutrina mais desmentida pelos factos! Multiplicaram as escolas e foi necessário alargar as cadeias.

$[\ldots]$

Implantada a escola leiga no terreno do natural pendor do homem para o mal, não se pode conservar ela indiferente e neutra como se anunciava: era de por força ser o instrumento apropriado para destruição de toda crença religiosa, nem outro é o seu objetivo, nem o negam seus preconizados (A PALAVRA, 13 jan. 1935, p. 1).
}

Os impressos são uma forma de construção discursiva que se consolida como parte constituinte das práticas sociais. Nesse sentido, o esforço da imprensa católica no Rio Grande do Sul segue a lógica nacional e vincula discursivamente o laico a algo negativo. De acordo com Novaes (2010), a Igreja Católica, desde o início do século XX, preocupava-se em caracterizar a má imprensa, caracterizando os jornais laicos e de outras religiões como representantes desta imprensa. A imprensa se constitui como estratégia significativa na mobilização da Igreja; no entanto, para credibilizar a leitura dos impressos católicos, descredibilizava os outros impressos. Passos (1986, p. 94) observa que "a imprensa católica era um dos recursos significativos e eficientes para viabilizar a missão eclesiástica, instruindo, educando, defendendo a fé e difundindo a doutrina católica".

A Igreja Católica, por meio da imprensa, dialoga com setores internos e externos à instituição, articula o laicato católico e estimula a criação de novos grupos. Através dos impressos é possível mapear uma rede de sociabilidade que se articula no interior da instituição para atuar em diversos espaços. O trecho abaixo, publicado no "Estrella do Sul", anuncia a organização citada. 
A 'Estrella do Sul', semanário genuinamente católico, inicia hoje um novo ano de sua benéfica publicação. É justo, pois, que os reverendos, vigários lhe ofereçam o mais decidido apoio, procurando franquear-lhe a entrada em todos os lares católicos. No intuito de se conseguir esse fim, queiram eles ingressar-se, seriamente, pelo referido jornal, angariando novas assinaturas, que, como as antigas, sejam pagas sem demora.

Essa propaganda deve ser feita pessoalmente, pelos reverendos, sacerdotes e com o valioso auxílio das corporações religiosas estabelecidas nas referidas igrejas.

Uma palavra de recomendação proferida na escola, no catecismo, antes da pregação, nas reuniões de diretoria das associações católicas será de grande utilidade.

Mas, essa propaganda constante e sistemática, além de se útil torna-se necessária e constitui um sagrado dever para o reverendo clero.

A 'Estrella do Sul' não representa apenas um criterioso repertório de abundantes informações, mas é, sobretudo, uma defensoria temida e acérrima dos ensinamentos e preceitos da Igreja.

O vigário que lhe nega amparo priva-se de um poderoso auxílio no desempenho de seus trabalhos apostólicos.

As revistas populares que se publicam dentro e fora do Estado, ainda que mereçam nossa inteira aprovação, não podem, de forma alguma, em face de sua finalidade especial, substituir a 'Estrella do Sul', redigida com muito carinho e indiscutível competência.

Para despertar maior interesse local, é mister que os Srs. vigários mandem regularmente notícias e informações com referência ao movimento social e religioso de suas paróquias (ESTRELLA DO SUL, 4 jan. 1930, p. 1).

Nota-se a recorrência do debate acerca da escola, sob duas abordagens: a valorização do espaço escolar e a necessidade de mudar o espaço escolar. A frase já destacada neste texto, retirada do jornal "Estrella do Sul", publicação do dia 07 dez. 1930 na página um, ilustra a afirmação feita sobre valorização do espaço escolar: "O pai que não manda seu filho à escola é um criminoso".

O debate sobre a presença do ensino religioso nas escolas é pauta nacional da Igreja Católica. Embora a primeira constituição republicana tenha estabelecido a laicidade nos estabelecimentos de ensino mantidos pelos poderes públicos, ocorre em 1926 a revisão constitucional que explicita a disputa em torno deste tema; o ensino religioso não voltou às escolas pela diferença de 11 votos. Francisco Campos foi um dos defensores da ementa constitucional que propunha o retorno do ensino religioso às escolas e perdeu na votação. Entretanto, em 1931, já como Ministro da Educação e Saúde do Governo Provisório, Francisco Campos estimulará Vargas a assinar o decreto $\mathrm{n}^{\circ}$ 19.941, de 30 de abril de 1931, que reintroduz de forma facultativa o ensino religioso nas escolas.

José Silvério Baía Horta (2005) apresenta de forma muito objetiva o pensamento de Francisco Campos, no que se refere à Igreja. "Para Campos, a doutrina católica não era apenas uma doutrina religiosa, mas uma doutrina de Estado. Ora, a razão de toda a crise pela qual 
passava o Brasil era que ao Estado brasileiro faltava uma doutrina" (HORTA. 2005, p. 149), o que, em sua opinião, só poderia ser o catolicismo.

A concessão realizada à Igreja Católica, através do decreto que permitia ensino religioso nas escolas, somada a algumas características da reforma educacional, acabaram por desagradar uma parte dos escolanovistas que, como reação a tais encaminhamentos, publicaram o Manifesto dos Pioneiros da Educação Nova, que produziu uma cisão definitiva no interior da Associação Brasileira de Educação, popularmente tratada pela sigla ABE.

O "entusiasmo pela educação" (NAGLE, 1974), que marcou a década de 1920, foi de certa forma responsável pela criação da ABE em 1924, que mantinha a ênfase na educação e na universalização do ensino primário como possibilidade de avançar no processo de desenvolvimento do país. A ABE consolidou um grupo de intelectuais que pensavam sobre a educação nacionalmente e defendiam pressupostos de uma escola moderna.

Por sua vez, a Igreja Católica não estava satisfeita com o decreto de 1931 e Alceu Amoroso Lima, diretor da revista "A Ordem” e presidente do Centro Dom Vital, afirmava que era necessário lutar para que os princípios básicos da ordem cristã orientassem a constituição do país. O decreto de 1931 representou uma vitória para o movimento católico, mas não era suficiente. A mobilização em torno da constituição seguiu em todo país. Destaco a seguir um trecho publicado pelo jornal católico "A palavra" que faz referência ao decreto e parabeniza o governo por tal iniciativa, mas estimula a organização dos professores em torno da constituinte.

Quando foi por ocasião do decreto do ensino religioso facultativo nas escolas, passaram-
se vários telegramas de felicitações ao governo. Mas esse decreto não era e nem é
definitivo. Pode ser anulado de um momento para o outro. Urge, pois, que os católicos,
mas especialmente os professores católicos, se unam em associações e empreguem todos
os seus esforços para que esse decreto se torne efeito (A PALAVRA, 4 set. 1932, p. 1).

No intuito de garantir suas reivindicações, a Igreja estabelece diversas estratégias de mobilização popular, dentre elas a criação da LEC (Liga Eleitoral Católica), em 1932. A Liga tinha como objetivo, em 1933, eleger constituintes comprometidos com os princípios defendidos pela Igreja Católica. Não estava ligada a nenhum partido político, mas era explicitamente anticomunista. Estimulava os católicos a votar e promovia candidatos comprometidos com os seus pressupostos. Nas eleições para constituinte de 1933, a LEC organizou uma grande campanha nacional e elaborou um programa mínimo, contendo três pontos: defesa da indissolubilidade do laço matrimonial e reconhecimento dos efeitos civis ao casamento religioso, 
incorporação legal do ensino religioso facultativo nos programas de escolas públicas e regulamentação da assistência religiosa facultativa nas Forças Armadas.

A LEC alistou eleitores católicos em todo o país, advogou em prol do voto feminino em sentido amplo, mapeou os candidatos que se comprometiam com o programa católico mínimo e indicou tais candidatos para votação. Por fim, a LEC conseguiu eleger a maioria dos candidatos que apoiou.

Todos os defensores da escola laica, - liberais, maços, bolcheviques et caterva -, devem estar, esta hora, descontentes e com forte razão. A vitória do ensino religioso nas escolas não pode sofrer contestação. Os resultados do seu estabelecimento nas diversas unidades brasileiras são extraordinários, não se registrando, até hoje nenhum dos inconvenientes apontados pelos inimigos da religião (A PALAVRA, 10 maio 1936, p. 2).

A Igreja assumiu uma postura moderna ao defender o direito de voto para as mulheres; no entanto, tal reivindicação pactua com a necessidade de eleger o máximo possível de candidatos comprometidos com a LEC. Nos impressos estudados, destacam-se diversas notícias direcionadas à mulher e orientando sobre o exercício do voto. Alguns textos estabelecem uma estratégia narrativa de convencimento da leitora a votar, o que pode indicar função relevante da Igreja Católica no estímulo à prática do voto feminino.

Após garantir uma vitória nas urnas, a Igreja investe internamente no fortalecimento da Ação Católica e convoca seus fiéis a assumirem tarefas em prol da instituição. Paralelamente, mantém a relação estável com o Estado, por intermédio do pacto de colaboração que constituiu uma parceria entre as instituições. De acordo com Schwartzman (1986), pelo menos três fatos demonstram como o projeto do pacto havia frutificado: as emendas religiosas foram incorporadas na constituição de 1934; Getúlio Vargas, em um ato de acatamento à autoridade da Igreja, casa-se no religioso, após anos de vínculo estritamente civil; e Gustavo Capanema é empossado no Ministério da Educação e Saúde, após negociações das quais participou Amoroso Lima, representante da intelectualidade católica.

A intervenção da Igreja Católica na década de 30 do século XX foi orientada pela disputa dos espaços institucionais e reorganização interna para atender às demandas impostas pela modernidade. De acordo com Dias (1993), a Igreja Católica organizou sua intervenção contra o laicismo, objetivando atingir dois grupos sociais identificados como a base e os intelectuais. A criação dos Círculos Operários e da Juventude Operária Cristã, na década de 30, estava diretamente relacionada à intenção de intervir junto à base, junto ao movimento do operariado no 
intuito de frear as manifestações comunistas neste setor. Os Círculos Operários e a Juventude Operária estimulavam a participação nos sindicatos, mas assumindo uma postura passiva no que se referia ao Estado.

Os assuntos tratados nos impressos se relacionam com política, economia, educação, religião, comportamento, entre outros. Os impressos estudados buscam dialogar com o leitor, tratam de assuntos gerais e desta forma ampliam seu potencial de intervenção. Os periódicos fazem indicações sobre em quem o eleitor deve votar, em qual escola a família deve matricular o seu filho, qual comportamento adequado para as meninas, meninos, senhoras, pais; sugerem filmes, livros; relatam acontecimentos como: assaltos, roubos, morte; divulga cursos gerais, divulgam os eventos da Igreja Católica, apresentam artigos sobre temas diversos; enfim, se consolidam como jornais atrativos.

No escopo desta proposta, cabe ressaltar que o impresso produz uma série de ideias vinculadas ao retorno do ensino religioso nas escolas e uma nova relação estabelecida entre Estado e Igreja Católica. Em 1942, uma nota no jornal “A Palavra” (A PALAVRA, 20 set. 1942, p. 01) relata a promoção de uma missa campal em prol da saúde de Getúlio Vargas e indica a participação de centenas de pessoas no evento; tal relato nos indica a relação política estabelecida entre Estado e Igreja no período.

Observa-se também que a socialização de ideias, possibilitada pelo impresso, se torna instrumento para organização de grupos vinculados à igreja católica e que atuam em espaços externos a ela, como, por exemplo, a Associação Católica de Professores. Tal instituição divulga e relata suas atividades no impresso; ao mesmo tempo sua ação é estabelecida para fora da Igreja, ou seja, o foco deste grupo organizado é a escola pública. Neste caso, o impresso funciona como mecanismo de apoio a processos socializadores e estabelece uma rede social entre os professores.

As construções discursivas eram posicionadas estrategicamente pela Igreja Católica e anunciavam que a "A religião era a base do progresso" (STAFFETTA RIO-GRANDENSE, 21 fev. 1934, p. 1). Os impressos apresentavam um padrão de comportamento a ser seguido por um bom católico e, nesse sentido, estimulava práticas que se aproximassem deste perfil idealizado. $\mathrm{O}$ exemplo do voto é interessante, pois o tom do discurso não era de convencimento, mas de orientação, como fica evidente no trecho a seguir: 


\begin{abstract}
LIGA ELEITORAL CATÓLICA
Declaração

A junta estadual da liga eleitoral católica, em obediência a sua alta finalidade, declara a seus eleitores que os mesmos, em consciência, não poderão absolutamente votar nos candidatos do Partido Libertador, constantes da chapa por este publicada; por enquanto, esse partido, no último congresso de Riviera, vetou e exclui de seu programa os postulados pelo que se batem os católicos.

Porto Alegre, 26 de abril de 1933 (ESTRELLA DO SUL, 27 abr. 1933, p. 1).
\end{abstract}

De acordo com a estrutura textual, entende-se uma orientação explícita aos católicos, "o bom católico não vota nos candidatos do Partido Libertador", e subentende-se que somente os maus católicos votam no partido libertador. Considerando que majoritariamente a população brasileira se declarava católica, o que se constrói discursivamente é que o Partido Libertador não deverá eleger seus candidatos, pois os católicos não votarão em tal partido.

\title{
Considerações finais
}

As informações que circulam nos impressos citados constroem e expressam representações (sobre fatos, contextos e conflitos) e disputam a adesão do leitor às mesmas. Chartier (1998, p. 14) observa que "no objeto impresso, o fato nada é para além da apresentação do texto e da imagem, que dão a ler ou a ver a sua representação".

Buscou-se, sob inspiração de Revel (1998), valorizar as migalhas de informação no intuito de compreender de que maneira tais detalhes podem dar acesso a lógicas sociais simbólicas que são dos grupos ou de conjuntos muito maiores. A campanha contra o partido libertador, citado anteriormente, indica o apoio da Igreja ao partido oponente. $\mathrm{O}$ apoio da Igreja pressupunha uma série de compromissos, dentre eles o retorno do ensino religioso às escolas públicas. Tais acordos aparecem de forma implícita nos nossos jornais, mas, se conectados com outros elementos do contexto nacional e local, nos possibilitam o entendimento sobre os interesses em disputa.

Na concepção disputada pela imprensa católica, a função da escola, mesmo a pública, é a de educar de acordo com os princípios do catolicismo. Os impressos estabelecem a família como primeiro espaço educativo e a escola como segundo; ao valorizar a família como instância educativa prioritária, delega para esta a decisão sobre a educação dos filhos e sugere que as famílias exijam do Estado uma educação de acordo com os seus princípios.

Por fim, os discursos apresentados nos impressos religiosos, vinculados à Igreja Católica, no estado do Rio Grande do Sul, anunciam algumas formas de organização utilizadas pela Igreja, 
os discursos por ela legitimados e as opções sociais e políticas da instituição, indicando potencial reflexivo sobre a educação no período, pois anunciam, através de suas representações, as forças presentes no campo educacional.

\section{Referências}

ALMEIDA, Maria das Graças Ataíde de. A república cristã: fé, ordem e progresso. In: HOMEM, Amadeu Carvalho; SILVA, Armando Malheiro da; ISAIA, Artur César (Org.). Progresso e religião: a república no Brasil e em Portugal 1889-1910. Coimbra: Imprensa da Universidade, 2007.

ALVES, Francisco das Neves. Imprensa e política: algumas reflexões acerca da investigação histórica. História em Revista, Pelotas, v. 7, p. 93-115, dez. 2001.

BICCAS, Maurilaine de Souza. O impresso como estratégia de formação: revista do ensino de Minas Gerais (1925 -1940). Belo Horizonte: Argvmentvm, 2008.

CHARTIER, Roger (Org.). As utilizações do objecto impresso. Portugal: Difel, 1998.

DIAS, Romualdo. A doutrina católica sobre a autoridade no Brasil 1922-1935. 1993. Tese

(Doutorado) - Instituto de Filosofia e Ciências Humanas - Universidade Estadual de Campinas, Campinas, 1993.

ESTRELLA DO SUL. Porto Alegre, 4 jan. 1930.

ESTRELLA DO SUL. Porto Alegre, 2 fev. 1930.

ESTRELLA DO SUL. Porto Alegre, 7 dez. 1930.

ESTRELLA DO SUL. Porto Alegre, 27 abr. 1933.

HORTA, José Silvério Bahia. A Constituição de 1934: comentários. In: FÁVERO, Osmar (Org.). A educação nas constituintes brasileiras (1823-1988). 3. ed. Campinas: Autores Associados, 2005.

LUSTOSA, Oscar de Figueiredo. Os bispos do Brasil e a imprensa. São Paulo: Edições Loyola, 1983.

MAGALDI, Ana Maria Bandeira de Mello. Páginas do professorado: um estudo sobre profissão e formação docente em periódicos católicos (anos 1930 - Brasil/Portugal). Revista SÍSIFO, Lisboa, n. 11, jan./abr. 2010.

NAGLE, Jorge. Educação e sociedade na Primeira República. São Paulo: E.P.U, 1974.

NOVAES, NÉVIO de. Intelectuais e igreja católica no Paraná: 1926-1938. Ponta Grossa: UEPG, 2010.

NÓVOA, Antônio. A imprensa de educação e ensino. In: BASTOS, Maria Helena Câmara; CATANI, Denise Bárbara (Org.). Educação em revista: a imprensa periódica e a história da educação. São Paulo: Escrituras, 1997.

A PALAVRA. Pelotas, 13 set. 1930.

A PALAVRA. Pelotas, 13 jan. 1935.

A PALAVRA. Pelotas, 4 set. 1932.

A PALAVRA. Pelotas, 10 maio 1936.

A PALAVRA. Pelotas, 20 set. 1942.

Quaestio, Sorocaba, SP, v. 19, n. 1, p. 69-85, abr. 2017. 
PASSOS, Mauro. A presença e o discurso da igreja na formação da classe trabalhadora em Belo Horizonte (1890 - 1930). 1986. Dissertação (Mestrado em Educação) - Universidade Federal de Minas Gerais, Belo Horizonte, 1986.

REVEL, Jacques. (Org.). Jogos de escalas: a experiência da microanálise. Rio de Janeiro: FGV, 1998.

SCHWARTZMAN, Simon. A política da igreja e a educação: o sentido de um pacto. Revista Religião e Sociedade, Rio de Janeiro, março 1986.

SOUZA, João Valdir Alves de. Igreja, educação e práticas culturais: a mediação religiosa no processo de produção/reprodução sociocultural na região do médio Jequitinhonha mineiro. 2000. Tese (Doutorado em Educação) - Pontifícia Universidade Católica de São Paulo, São Paulo, 2000.

STAFFETTA RIO-GRANDENSE. Caxias do Sul, 21 fev. 1934.

VIEIRA, Carlos Eduardo. Jornal diário como fonte e como tema para a pesquisa em História da Educação: um estudo entre imprensa, intelectuais e modernidade nos anos de 1920. In: OLIVEIRA, Marcus Aurélio Taborda de (Org.). Cinco estudos em história e historiografia da educação. Belo Horizonte: Autêntica, 2007.

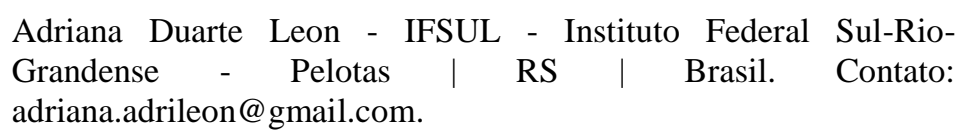

Artigo recebido em: 18 ago. 2015 e aprovado em: 2 fev. 2016.

Quaestio, Sorocaba, SP, v. 19, n. 1, p. 69-85, abr. 2017. 